\title{
Monoamine Oxidase Inhibition by Kavalactones from Kava (Piper Methysticum)
}

Authors

Denise Prinsloo, Sandra van Dyk, Anél Petzer, Jacobus P. Petzer

Affiliation

Pharmaceutical Chemistry, School of Pharmacy and Centre

of Excellence for Pharmaceutical Sciences, North-West

University, Potchefstroom, South Africa

Key words

monoamine oxidase, inhibition, kava, Piper methysticum, Piperaceae, kavain, yangonin

received January 29, 2019

revised August 13, 2019

accepted September 1, 2019

Bibliography

DOI https://doi.org/10.1055/a-1008-9491

Published online September 20, 2019 | Planta Med 2019; 85:

1136-1142 @ Georg Thieme Verlag KG Stuttgart · New York I ISSN 0032-0943

Correspondence

Prof. Jacobus P. Petzer

Pharmaceutical Chemistry, School of Pharmacy and Centre

of Excellence for Pharmaceutical Sciences, North-West

University

11 Hoffman street, 2531 Potchefstroom, South Africa

Phone: + 27182992206

jacques.petzer@nwu.ac.za

\section{ABSTRACT}

Monoamine oxidases (MAOs) are key metabolic enzymes for neurotransmitter and dietary amines and are targets for the treatment of neuropsychiatric and neurodegenerative disorders. This study examined the MAO inhibition potential of kavain and other kavalactones from the roots of kava (Piper methysticum), a plant that has been used for its anxiolytic properties. ( \pm )-Kavain was found to be a good potency in vitro inhibitor of human MAO-B with an $\mathrm{IC}_{50}$ of $5.34 \mu \mathrm{M}$. ( \pm )-Kavain is a weaker MAO-A inhibitor with an $\mathrm{IC}_{50}$ of $19.0 \mu \mathrm{M}$. Under the same experimental conditions, the reference MAO inhibitor, curcumin, displays $\mathrm{IC}_{50}$ values of $5.01 \mu \mathrm{M}$ and $2.55 \mu \mathrm{M}$ for the inhibition of MAO-A and MAO-B, respectively. It was further established that $( \pm)$-kavain interacts reversibly and competitively with MAO-A and MAO-B with enzyme-inhibitor dissociation constants $\left(K_{i}\right)$ of 7.72 and $5.10 \mu \mathrm{M}$, respectively. Curcumin in turn, displays a $\mathrm{K}_{\mathrm{i}}$ value of $3.08 \mu \mathrm{M}$ for the inhibition of MAO-A. Based on these findings, other kavalactones (dihydrokavain, methysticin, dihydromethysticin, yangonin, and desmethoxyyangonin) were also evaluated as MAO inhibitors in this study. Yangonin proved to be the most potent MAO inhibitor with $\mathrm{IC}_{50}$ values of 1.29 and $0.085 \mu \mathrm{M}$ for MAO-A and MAO-B, respectively. It may be concluded that some of the central effects (e.g., anxiolytic) of kava may be mediated by MAO inhibition.

\section{Introduction}

Monoamine oxidase (MAO) is a flavin adenine dinucleotide (FAD)containing enzyme that is attached to the outer mitochondrial membrane. MAOs are key metabolic enzymes that regulate the levels of neurotransmitters and dietary amines in both the central and peripheral tissues [1,2]. MAO exists as 2 distinct isoforms, MAO-A and MAO-B, which are encoded by separate genes. Although the MAO isoforms are approximately $70 \%$ identical on the amino acid sequence level, in many instances they exhibit different substrate specificities $[3,4]$. In this regard, serotonin is a specific substrate for MAO-A while 2-phenylethylamine and benzylamine are specific substrates for the MAO-B isoform [5]. Considerable overlap in substrate specificity also occur with for example dopamine, adrenaline, noradrenaline, and tyramine acting as substrates for both isoforms. The MAOs often also display different inhibitor specificities. The irreversible inhibitors clorgyline and selegiline are thus specific inhibitors of MAO-A and MAO-B, respectively, and have been used to distinguish between the 2 isoforms in pharmacological studies [6].

Since the MAOs are involved in the metabolic breakdown of neurotransmitters, they are of considerable pharmacological and therapeutic interest [5]. MAO-A inhibitors have been used clinically to treat depressive illness and act by inhibiting the central metabolism of serotonin and noradrenalin, thereby elevating their levels [7]. MAO-B inhibitors, in turn, have been used to treat Parkinson's disease and act by reducing the central metabolism of dopamine [8]. MAO-B inhibitors are thus frequently combined with L-dopa, the metabolic precursor of dopamine, in Parkinson's disease treatment [9]. MAO inhibitors may also reduce the formation of metabolic by-products of MAO catalysis, most notably hydrogen peroxide $[2,10]$. The MAO-mediated formation of hydrogen peroxide and its role in generating reactive oxygen species have been implicated the cellular- and neurodegeneration in car- 


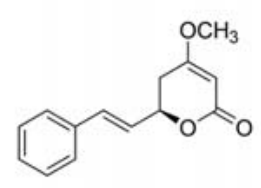

(+)-Kavain

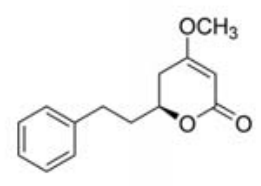

(+)-7,8-Dihydrokavain

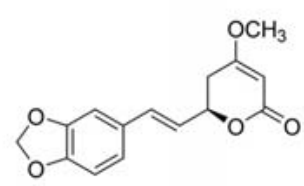

(+)-Methysticin

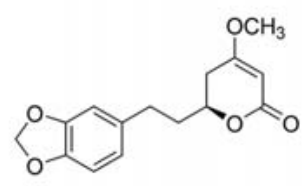

(+)-7,8-Dihydromethysticin<smiles>COc1ccc(/C=C/c2cc(OC)cc(=O)o2)cc1</smiles>

Yangonin<smiles></smiles>

Desmethoxyyangonin<smiles>COc1ccc(CCC2CC(OC)C=C(C(=O)O)O2)cc1</smiles>

$(+)-5,6,7,8-$ Tetrahydroyangonin

- Fig. 1 Structures of kavalactones from P. methysticum.

diovascular disease and Parkinson's disease. MAO-A inhibitors have thus been advocated as potential treatment of congestive heart failure while MAO-B inhibitors may act as potential neuroprotective agents in neurodegenerative disorders [2,11-13]. Interestingly, MAO-A activity has been found to be increased in certain types of cancer, and MAO-A inhibitors have thus been investigated as potential treatment of prostate cancer [14].

This study investigates the MAO inhibition properties of kavain, a major constituent of Piper methysticum (Piperaceae, G. Forster), a pepper plant called kava, as well as other kavalactones present in this plant ( $\bullet$ Fig. 1) $[15,16]$. The root of the kava plant is used as a cultural beverage prepared in water or coconut milk and is used for religious, social, and medicinal purposes by South Pacific island inhabitants. The recreational use of kava is associated with a calming effect and kava extracts have subsequently been evaluated in clinical trials for the treatment of anxiety disorder [1720]. In fact, in some Western societies, kava is used to relieve stress-induced anxiety and insomnia. Other pharmacological effects of extracts of the kava plant include anti-inflammatory and analgesic properties [21,22]. The constituents of kava exert neurological effects, in part, due to their lipophilic profile, which facilitates entry into the central nervous system [23]. It should be noted that some reports suggest that kava may potentially induce hepatotoxicity, although the mechanism of toxicity is not yet clear [24]. The major constituents are subdivided into 3 groups: kavalactones, chalcones, and conjugated diene ketones. The kavalactones (also known as kavapyrones) include (+)-kavain, (+)-7,8-dihydrokavain, (+)-methysticin, (+)-7,8-dihydromethysticin, yangonin, desmethoxyyangonin, and (+)-5,6,7,8-tetrahydroyangonin as the most abundant kavalactones [25]. The kavalactones undergo 4 degradation processes, which are hydroxylation of the lactone ring and the aromatic ring at C-12, demethylation of the 4-methoxyl group, 7,8-double bond reduction, and dehydration. The molecular targets of the kavalactones include histamine receptors, voltage-gated channels $\left(\mathrm{Na}^{+}\right.$and $\left.\mathrm{Ca}^{2+}\right)$, opioid receptors, the dopamine type- 2 receptor, and $\gamma$-aminobutyric acid type A receptors [26-30]. A literature survey also reveals that these kavalactones have been found to act as inhibitors of human platelet MAO-B [31]. The inhibition of MAO-A by kavalactones have, how- ever, not been reported. This study therefore investigates the human MAO-A inhibition properties of some of the kavalactones that are most abundant in the kava plant, and also examines the reversibility and mode of MAO inhibition by $( \pm$ )-kavain and yangonin. Curcumin was included in this study as reference MAO inhibitor [32]. The potential MAO-A inhibition properties of kavalactones may be particularly relevant in defining the mechanism by which kava extracts exert an anxiolytic effect.

\section{Results and Discussion}

The inhibition studies were carried out with the recombinant human MAOs as enzyme sources and kynuramine served as the nonselective substrate [33]. Examples of sigmoidal curves for the inhibition of the MAOs are given in - Fig. 2 . For this study, the natural product and known MAO inhibitor curcumin served as reference inhibitor [32].

The results of the MAO inhibition studies are given in $>$ Table 1 and show that $( \pm)$-kavain is a noteworthy inhibitor of MAO-B with an $I_{50}$ value of $5.34 \mu \mathrm{M}$. The natural occurring enantiomer, (+)-kavain, exhibits similar MAO-B inhibition potency with an $\mathrm{IC}_{50}$ of $4.34 \mu \mathrm{M}$. This inhibition potency is within the same range as that of the reference MAO inhibitor curcumin, which exhibits $I_{50}$ values of 5.01 and $2.55 \mu \mathrm{M}$ for the inhibition of MAO-A and $M A O-B$, respectively. A literature survey shows that kavain is known to inhibit MAO-B [31]. The MAO-B inhibition properties of kavain as well as other kavalactones from the kava plant (dihydrokavain, methysticin, dihydromethysticin, yangonin, and desmethoxyyangonin) were reported and the literature $\mathrm{IC}_{50}$ values are given in $>$ Table 1 . The inhibition of MAO-A by kavain and kavalactones have, however, not been reported. As shown, $( \pm)$-kavain inhibits MAO-A with an $\mathrm{IC}_{50}$ of $19.0 \mu \mathrm{M}$. The $(+)$-enantiomer is slightly lower in potency with an $\mathrm{IC}_{50}$ of $32.1 \mu \mathrm{M}$. As mentioned in the introduction, the potential MAO-A inhibition properties of kavalactones may be particularly relevant in defining the mechanism by which kava extracts exert an anxiolytic effect. This study therefore set out to determine the MAO-A inhibition properties of other kavalactones that are present in kava. The results show that some of the kavalactones are indeed inhibitors of MAO-A with 


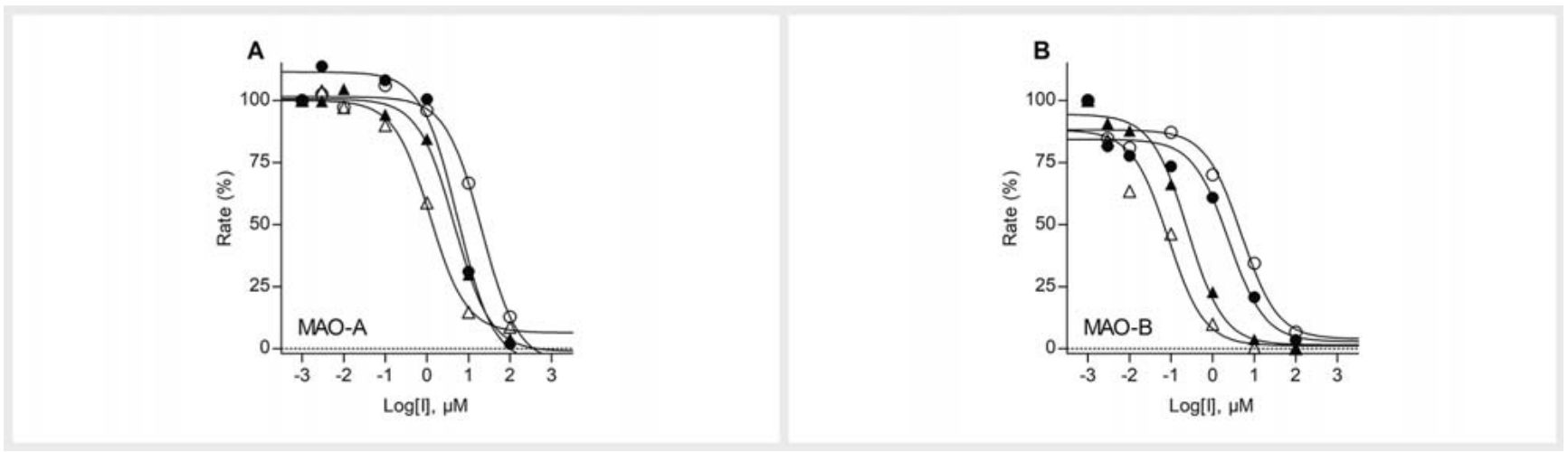

- Fig. 2 Sigmoidal plots for the inhibition of MAO-A (panel A) and MAO-B (panel B) by ( \pm )-kavain (open circles), curcumin (filled circles), yangonin (open triangles), and desmethoxyyangonin (filled triangles).

- Table 1 The $\mathrm{IC}_{50}$ values for the inhibition of recombinant human MAO-A and MAO-B by constituents of $P$. methysticum.

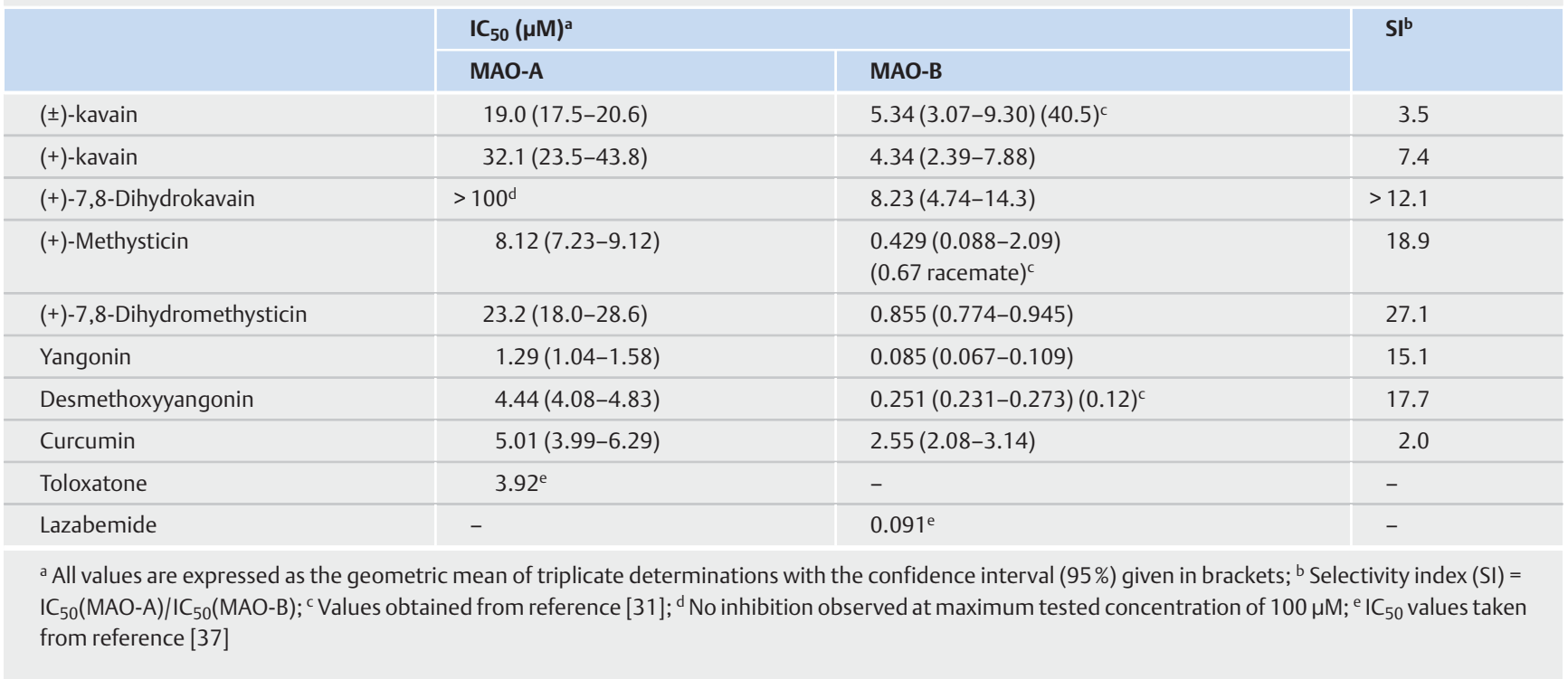

yangonin $\left(\mathrm{IC}_{50}=1.29 \mu \mathrm{M}\right)$ and desmethoxyyangonin $\left(\mathrm{IC}_{50}=\right.$ $4.44 \mu \mathrm{M})$ acting as the most potent inhibitors. These inhibition potencies are in the same range as that recorded for the reference MAO-A inhibitor, toloxatone. It is interesting to note that yangonin and desmethoxyyangonin are the only planar compounds among the kavalactones (e.g., possessing the aromatic 2-pyrone), which suggest that these compounds fit and interact better in the MAO-A active site. While this observation may explain their good MAO-A inhibition potencies, further investigation, possibly including molecular docking experiments, will be required to address this point. Numerous planar compounds such as harmine are reported to be good potency MAO-A inhibitors [34]. Interestingly, with the exception of desmethoxyyangonin, the MAO-B inhibition potencies recorded for the kavalactones are higher than those reported, which is possibly due to different experimental conditions [31]. Yangonin, in particular, is a high potency MAO-B inhibitor $\left(\mathrm{IC}_{50}=0.085 \mu \mathrm{M}\right)$. In fact, 4 of the 6 kavalactones inhibit MAO-B with $\mathrm{IC}_{50}$ values in the sub-micromolar range.
Reversibility of MAO inhibition, particularly of the MAO-A isoform, is an important factor of MAO inhibitors to consider. Irreversible MAO-A inhibitors are associated with the "cheese reaction", which is a potentially fatal increase in blood pressure that may occur when tyramine-containing foods are taken with irreversible MAO-A inhibitors [35,36]. Reversible MAO-A inhibitors and $M A O-B$ inhibitors do not cause the cheese reaction [2,35]. The reversibility of MAO-A and MAO-B inhibition was thus investigated for ( \pm )-kavain (the major constituent of $P$. methysticum), yangonin (the most potent MAO inhibitor in this study), and curcumin, the latter serving as reference inhibitor. For this purpose, dialysis experiments were carried out. MAO-A or MAO-B and the test inhibitors [( \pm )-kavain, yangonin and curcumin] were firstly pre-incubated (at a concentration of $4 \times \mathrm{IC}_{50}$ ) and subsequently dialyzed. The incubation mixtures were diluted 2 -fold to yield an inhibitor concentration of $2 \times I C_{50}$, and the residual MAO-A and MAO-B activities were measured. For comparison, the residual MAO-A and MAO-B activities in non-dialyzed pre-incubations of the enzyme 

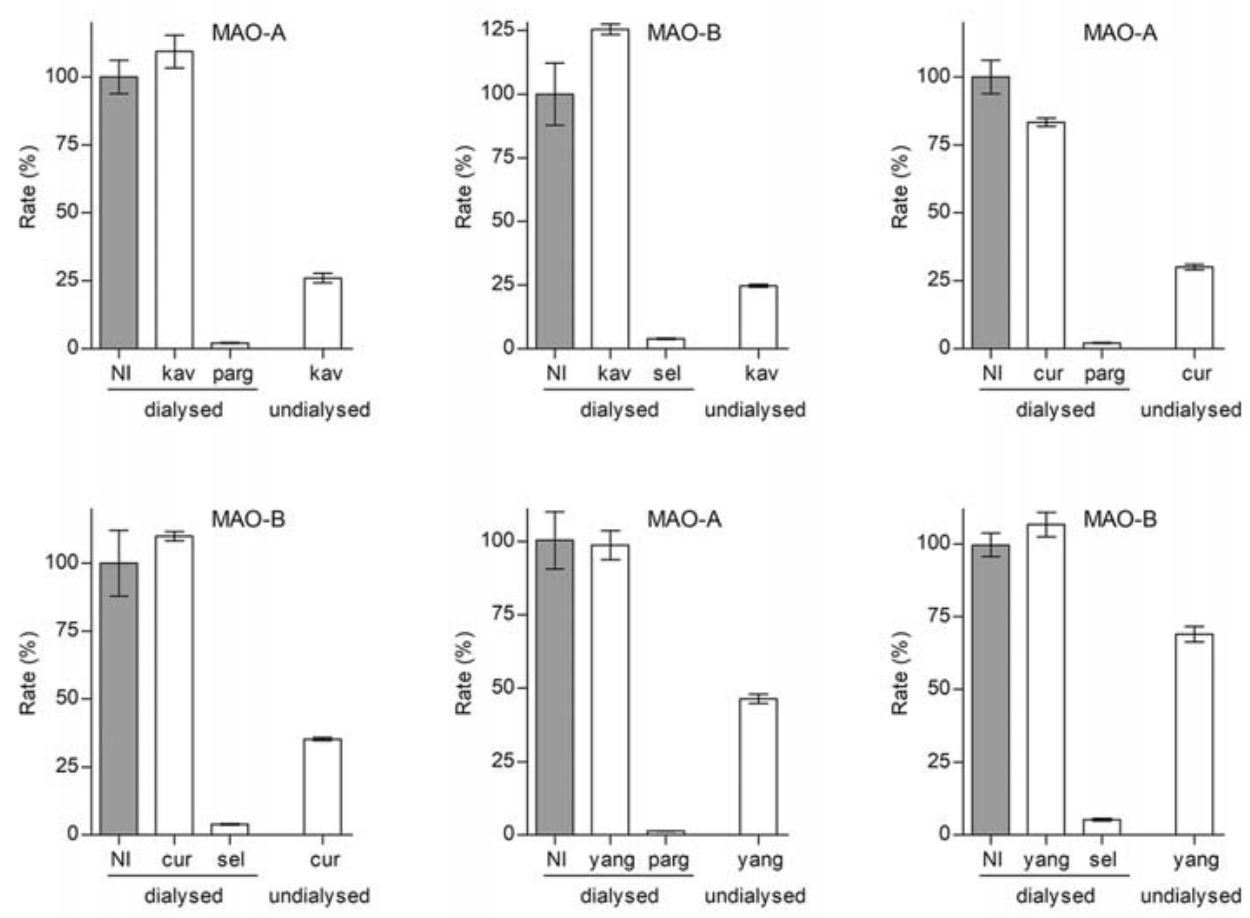

- Fig. 3 Reversibility of MAO-A and MAO-B inhibition by kavalactones. The MAO enzymes and the test inhibitors (at a concentration of $4 \times I_{50}$ ) were incubated for $15 \mathrm{~min}$, dialyzed for $24 \mathrm{~h}$, and the residual enzyme activities were measured. Similar incubation and dialysis of the enzyme in the absence of inhibitor, and presence of the irreversible inhibitors, pargyline, and selegiline, were also carried out. The residual activities of undialyzed mixtures of the MAO enzymes and the test inhibitors were also recorded. kav: ( \pm )-kavain; cur: curcumin; yang: yangonin; parg: pargyline; sel: selegiline; NI: no inhibitor.

and test inhibitors were also measured. As negative and positive controls, respectively, similar dialysis experiments were carried out in the absence of test inhibitor and presence of the irreversible MAO-A and MAO-B inhibitors, pargyline, and selegiline, respectively.

The results of the dialysis experiments are given in $\mathbf{~ F i g . ~} \mathbf{3}$ and show that $( \pm)$-kavain, yangonin, and curcumin are reversible inhibitors of MAO-A. After dialysis, MAO-A activity is recovered to $110 \%, 99 \%$, and $83 \%$ compared to the negative control value $(100 \%)$ for $( \pm)$-kavain, yangonin, and curcumin, respectively. As anticipated, inhibition of MAO-A persists in non-dialyzed pre-incubations with the residual activities at $26 \%, 46 \%$, and $30 \%$, respectively. For the positive control pargyline, dialysis does not restore catalytic activity with the residual activity at $1.2-2.2 \%$. It may thus be concluded that $( \pm)$-kavain, yangonin, and curcumin are reversible inhibitors of MAO-A.

$( \pm)$-Kavain, yangonin and curcumin were also found to be reversible inhibitors of MAO-B. After dialysis, MAO-B activity is restored to $125 \%, 106 \%$, and $110 \%$ compared to the negative control for ( \pm )-kavain, yangonin, and curcumin, respectively. In contrast, after pre-incubation of MAO-B with selegiline, dialysis does not restore catalytic activity with the residual activity at 3.9-5.2\%. Inhibition of MAO-B by $( \pm)$-kavain, yangonin, and curcumin also persists in non-dialyzed pre-incubations with the residual activities at $25 \%, 69 \%$, and $35 \%$, respectively.
To determine whether $( \pm)$-kavain, yangonin, and the reference inhibitor, curcumin, are competitive inhibitors of MAO-A, sets of Lineweaver-Burk plots were constructed ( $\bullet$ Fig. 4). The Lineweaver-Burk plots for the inhibition of MAO-A by ( \pm )-kavain, yangonin, and curcumin were found to be linear and to intersect on the $y$-axis. This suggests that the test inhibitors are competitive inhibitors of MAO-A and further supports the findings of the dialysis study that concluded that these inhibitors are reversible MAO-A inhibitors. From replots of the slopes of the Lineweaver-Burk plots versus inhibitor concentration, $\mathrm{K}_{\mathrm{i}}$ values $\left(\mathrm{K}_{\mathrm{i}}=-\mathrm{x}\right.$ when $\left.\mathrm{y}=0\right)$ of $7.72,1.12$, and $3.08 \mu \mathrm{M}$ are estimated for $( \pm)$-kavain, yangonin, and curcumin, respectively. A similar set of Lineweaver-Burk plots were constructed for the inhibition of MAO-B by $( \pm)$-kavain and yangonin. These plots show that $( \pm)$-kavain and yangonin also are competitive inhibitors of MAO-B with a $\mathrm{K}_{i}$ values of 5.10 and $0.226 \mu \mathrm{M}$. This finding is in accordance to the literature report on the inhibition of human platelet MAO-B by kavain and other kavalactones [31].

In conclusion, kavain was found to be a moderately potent MAO inhibitor. Although MAO-B inhibition by kavain is known, it is shown for the first time that this compound also inhibits MAO-A. Other kavalactones were also evaluated as MAO inhibitors and yangonin proved to be the most potent MAO inhibitor. In fact, yangonin may be considered a high potency MAO-B inhibitor, with activity comparable to that of the reference MAO-B inhibitor, lazabemide [37]. The MAO-A inhibition potency of yangonin may 

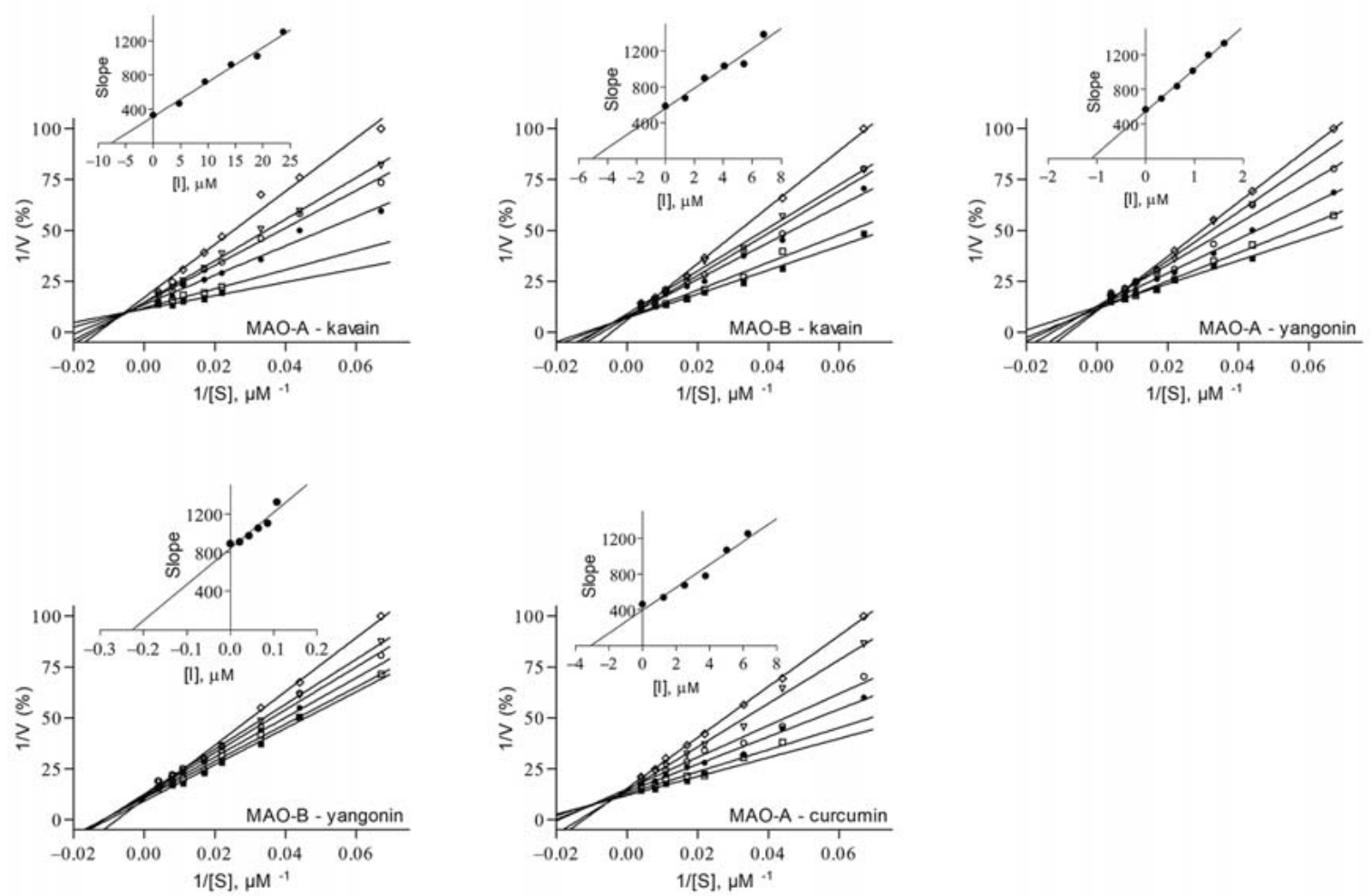

- Fig. 4 Lineweaver-Burk plots for the inhibition of MAO-A and MAO-B by $( \pm)$-kavain, yangonin, and curcumin. Plots were constructed in the absence of inhibitors (filled squares) and presence of various concentrations of the test inhibitors $\left(1 / 4 \times I_{50}, 1 / 2 \times I C_{50}, 3 / 4 \times I C_{50}, 1 \times I C_{50}\right.$, and $\left.1 \frac{1}{4} \times I C_{50}\right)$. The insets are graphs of the slopes of the Lineweaver-Burk plots versus inhibitor concentration.

also be considered good and is in a similar range as that of toloxatone. It is suggested that the planarity of yangonin mediates its higher MAO-A inhibition potency compared to kavain. It may be concluded that some of the central effects (e.g., anxiolytic) of kava may be mediated by MAO inhibition.

\section{Materials and Methods}

\section{Instrumentation and materials}

Fluorescence spectrophotometry was carried out using a Varian Cary Eclipse fluorescence spectrophotometer. Microsomes from insect cells containing recombinant human MAO-A and MAO-B $(5 \mathrm{mg}$ protein $/ \mathrm{mL}$ ) and kynuramine dihydrobromide were obtained from Sigma. ( \pm )-Kavain (>95\%), (+)-7,8-dihydrokavain (>98\%), (+)-methysticin (>98\%), (+)-7,8-dihydromethysticin $(>90 \%)$, yangonin (>95\%), desmethoxyyangonin (>95\%), and curcumin (>98\%) were purchased from Sigma. (+)-Kavain (98\%) was obtained from Carbosynth.

\section{$\mathrm{IC}_{50}$ value determinations}

$\mathrm{IC}_{50}$ values for the inhibition of MAO were measured by using the recombinant human MAO-A and MAO-B enzymes [38]. The enzyme reactions were carried out in white 96-well microtiter plates (Eppendorf) in potassium phosphate buffer (pH7.4, $100 \mathrm{mM}$, made isotonic with $\mathrm{KCl}$ ). The final volume of the reactions was $200 \mu \mathrm{L}$ and contained kynuramine $(50 \mu \mathrm{M})$, the test inhibitors $(0.003-100 \mu \mathrm{M})$, and MAO-A (0.0075 mg protein $/ \mathrm{mL})$ or MAO-B $(0.015 \mathrm{mg}$ protein $/ \mathrm{mL})$. Stock solutions of the test inhibitors were prepared in DMSO and added to the reactions to yield a final concentration of $4 \%$. Reactions serving as negative controls were carried out in the absence of inhibitor. The enzyme reactions were initiated with the addition of the MAO enzymes and were subsequently incubated for $20 \mathrm{~min}$ at $37^{\circ} \mathrm{C}$ in a convection oven. At endpoint, the reactions were terminated with the addition of $80 \mu \mathrm{L}$ sodium hydroxide ( $2 \mathrm{~N}$ ) and the concentration of 4-hydroxyquinoline, the product of kynuramine oxidation by MAO, was measured by fluorescence spectrophotometry $\left(\lambda_{\mathrm{ex}}=310 \mathrm{~nm}\right.$; $\lambda_{\mathrm{em}}=400 \mathrm{~nm}$ ) [33]. For this purpose, a linear calibration curve was constructed with authentic 4-hydroxyquinoline (0.047$1.56 \mu \mathrm{M})$. The rates of MAO-catalyzed 4-hydroxyquinoline formation thus measured were fitted to the one site competition model of the Prism 5 software package (GraphPad). This gave sigmoidal plots of rate versus logarithm of inhibitor concentration from which the $I C_{50}$ values were estimated. $I C_{50}$ values were measured in triplicate and are reported as the geometrical mean with $95 \%$ confidence intervals. 


\section{Dialysis studies}

Dialysis was carried out with Slide-A-Lyzer dialysis cassettes (Thermo Scientific) with a molecular weight cutoff of 10000 and a sample volume capacity of $0.5-3 \mathrm{~mL}$ [38]. The test inhibitor (at a concentration equal to $\left.4 \times \mathrm{IC}_{50}\right)$ and $\mathrm{MAO}(0.03 \mathrm{mg}$ protein $/ \mathrm{mL})$ were prepared to a final volume of $0.8 \mathrm{~mL}$ in the dialysis buffer (potassium phosphate buffer, $100 \mathrm{mM}$, pH 7.4, 5\% sucrose). Stock solutions of the inhibitor were prepared in DMSO and added to the buffer to yield $4 \%$ DMSO. These samples were pre-incubated for $15 \mathrm{~min}$ at $37^{\circ} \mathrm{C}$ and were subsequently dialyzed at $4{ }^{\circ} \mathrm{C}$ in $80 \mathrm{~mL}$ of dialysis buffer. The dialysis buffer was replaced with fresh buffer at $3 \mathrm{~h}$ and $7 \mathrm{~h}$ after the start of dialysis. As positive controls, MAO-A and MAO-B were similarly pre-incubated and dialyzed in the presence of the irreversible inhibitor, pargyline $\left(\mathrm{IC}_{50}=13 \mu \mathrm{M}\right)$ and selegiline $\left(I C_{50}=0.079 \mu \mathrm{M}\right)$, respectively $[39,40]$. As negative control, dialysis of the enzyme was carried out in the absence of the inhibitor. After $24 \mathrm{~h}$ of dialysis, $250 \mu \mathrm{L}$ of the dialyzed samples were diluted 2 -fold with the addition of $250 \mu \mathrm{L}$ kynuramine (dissolved in potassium phosphate buffer, $100 \mathrm{mM}, \mathrm{pH} 7.4$, made isotonic with $\mathrm{KCl}$ ) to yield reactions with a final volume of $500 \mu \mathrm{L}$ and containing kynuramine $(50 \mu \mathrm{M})$, MAO $(0.015 \mathrm{mg}$ protein $/ \mathrm{mL})$, and test inhibitor $\left(2 \times I C_{50}\right)$. The reactions (prepared in $1.5 \mathrm{~mL} \mathrm{mi}$ crocentrifuge tubes) were incubated at $37^{\circ} \mathrm{C}$ in a water bath and after 20 min were terminated with the addition of $400 \mu \mathrm{L}$ sodium hydroxide $(2 \mathrm{~N})$. After addition of $1000 \mu \mathrm{L}$ water, the concentrations of 4-hydroxyquinoline were measured by fluorescence spectrophotometry $\left(\lambda_{\mathrm{ex}}=310 \mathrm{~nm} ; \lambda_{\mathrm{em}}=400 \mathrm{~nm}\right.$ ) employing a $3.5 \mathrm{~mL}$ quartz cuvette (pathlength $10 \times 10 \mathrm{~mm}$ ). To quantify 4-hydroxyquinoline, a linear calibration curve was constructed with authentic 4-hydroxyquinoline (0.047-1.56 $\mu \mathrm{M})$. For comparison, undialyzed mixtures of MAO and the test inhibitor were maintained at $4{ }^{\circ} \mathrm{C}$ for $24 \mathrm{~h}$ and subsequently diluted 2 -fold and assayed as above. All reactions were carried out in triplicate and the residual enzyme catalytic rates were expressed as mean \pm standard deviation (SD).

\section{Lineweaver-Burk plots and $\mathrm{K}_{\mathrm{i}}$ value calculations}

To determine the mode of MAO inhibition of selected inhibitors, sets consisting of 6 Lineweaver-Burk plots were constructed [38]. The first plot was constructed in the absence of inhibitor while the remaining 5 plots were constructed in the presence of different concentrations of the test inhibitor: $1 / 4 \times I C_{50}, 1 / 2 \times I C_{50}, 3 / 4 \times I C_{50}$, $1 \times I C_{50}$, and $1 \frac{11 / 4}{} \times I C_{50}$. The enzyme substrate, kynuramine, was used at concentrations ranging from 15 to $250 \mu \mathrm{M}$ while the final enzyme concentration was $0.015 \mathrm{mg}$ protein $/ \mathrm{mL}$. All incubations were carried out in $1.5 \mathrm{~mL}$ microcentrifuge tubes to a volume of $500 \mu \mathrm{L}$. The MAO catalytic activities were measured by fluorescence spectrophotometry as described for the dialysis study. $K_{i}$ values were estimated from plots of the slopes of the Lineweaver-Burke plots versus inhibitor concentration, where the $x$-axis intercept equals $-\mathrm{K}_{\mathrm{i}}$.

\section{Acknowledgements}

This work was supported by grants from the National Research Foundation (NRF) of South Africa (Grant specific unique reference numbers [UID] 85642, 96180). Opinions expressed and conclusions arrived at are those of the authors and therefore the NRF does not accept any liability in regard thereto.

\section{Conflict of Interest}

The authors declare that they have no conflict of interest.

\section{References}

[1] Glover V, Sandler M, Owen F, Riley G]. Dopamine is a monoamine oxidase B substrate in man. Nature 1977; 265: 80-81

[2] Youdim MB, Bakhle YS. Monoamine oxidase: isoforms and inhibitors in Parkinson's disease and depressive illness. Br J Pharmacol 2006; 147 Suppl 1: S287-S296

[3] Bach AW, Lan NC, Johnson DL, Abell CW, Bembenek ME, Kwan SW, Seeburg PH, Shih JC. CDNA cloning of human liver monoamine oxidase $A$ and $B$ : molecular basis of differences in enzymatic properties. Proc Natl Acad Sci U S A 1988; 85: 4934-4938

[4] Shih JC, Chen K, Ridd MJ. Monoamine oxidase: from genes to behavior Annu Rev Neurosci 1999; 22: 197-217

[5] Youdim MB, Edmondson D, Tipton KF. The therapeutic potential of monoamine oxidase inhibitors. Nat Rev Neurosci 2006; 7: 295-309

[6] Ramsay RR. Inhibitor design for monoamine oxidases. Curr Pharm Des 2013; 19: 2529-2539

[7] Shulman KI, Herrmann N, Walker SE. Current place of monoamine oxidase inhibitors in the treatment of depression. CNS Drugs 2013; 27 : 789-797

[8] LeWitt PA, Taylor DC. Protection against Parkinson's disease progression: clinical experience. Neurotherapeutics 2008; 5: 210-225

[9] Henchcliffe C, Schumacher HC, Burgut FT. Recent advances in Parkinson's disease therapy: use of monoamine oxidase inhibitors. Expert Rev Neurother 2005; 5: 811-821

[10] Edmondson DE. Hydrogen peroxide produced by mitochondrial monoamine oxidase catalysis: biological implications. Curr Pharm Des 2014; 20: $155-160$

[11] Umbarkar P, Singh S, Arkat S, Bodhankar SL, Lohidasan S, Sitasawad SL. Monoamine oxidase-A is an important source of oxidative stress and promotes cardiac dysfunction, apoptosis, and fibrosis in diabetic cardiomyopathy. Free Radic Biol Med 2015; 87: 263-273

[12] Kaludercic N, Carpi A, Nagayama T, Sivakumaran V, Zhu G, Lai EW, Bedja D, De Mario A, Chen K, Gabrielson KL, Lindsey ML, Pacak K, Takimoto E, Shih JC, Kass DA, Di Lisa F, Paolocci N. Monoamine oxidase B prompts mitochondrial and cardiac dysfunction in pressure overloaded hearts. Antioxid Redox Signal 2014; 20: 267-280

[13] Manni ME, Rigacci S, Borchi E, Bargelli V, Miceli C, Giordano C, Raimond L, Nediani C. Monoamine oxidase is overactivated in left and right ventricles from ischemic hearts: an intriguing therapeutic target. Oxid Med Cell Longev 2016; 2016: 4375418

[14] Flamand V, Zhao H, Peehl DM. Targeting monoamine oxidase A in advanced prostate cancer. J Cancer Res Clin Oncol 2010; 136: 1761-1771

[15] Lebot V, Merlin M, Lindstrom L. Kava - the pacific Elixir: the definitive Guide to its Ethnobotony, History, and Chemistry. Rochester: Healing Arts Press; 1997: 1-272

[16] Cairney S, Maruff P, Clough AR. The neurobehavioural effects of kava. Aust N Z J Psychiatry 2002; 36: 657-662 
[17] Sarris J, Kavanagh DJ, Byrne G, Bone KM, Adams J, Deed G. The Kava Anxiety Depression Spectrum Study (KADSS): a randomized, placebocontrolled crossover trial using an aqueous extract of Piper methysticum. Psychopharmacology (Berl) 2009; 205: 399-407

[18] Sarris J, Stough C, Bousman CA, Wahid ZT, Murray G, Teschke R, Savage $\mathrm{KM}$, Dowell A, Ng C, Schweitzer I. Kava in the treatment of generalized anxiety disorder: a double-blind, randomized, placebo-controlled study. J Clin Psychopharmacol 2013; 33: 643-648

[19] Sarris J, Stough C, Teschke R, Wahid ZT, Bousman CA, Murray G, Savage $\mathrm{KM}$, Mouatt P, $\mathrm{Ng} \mathrm{C}$, Schweitzer I. Kava for the treatment of generalized anxiety disorder RCT: analysis of adverse reactions, liver function, addiction, and sexual effects. Phytother Res 2013; 27: 1723-1728

[20] Savage KM, Stough CK, Byrne G], Scholey A, Bousman C, Murphy ], Macdonald P, Suo C, Hughes M, Thomas S, Teschke R, Xing C, Sarris J. Kava for the treatment of generalised anxiety disorder (K-GAD): study protocol for a randomised controlled trial. Trials 2015; 16: 493

[21] Wu D, Yu L, Nair MG, DeWitt DL, Ramsewak RS. Cyclooxygenase enzyme inhibitory compounds with antioxidant activities from Piper methysticum (kava kava) roots. Phytomedicine 2002; 9: 41-47

[22] Jamieson DD, Duffield PH. The antinociceptive actions of kava components in mice. Clin Exp Pharmacol Physiol 1990; 17: 495-507

[23] Keledjian J, Duffield PH, Jamieson DD, Lidgard RO, Duffield AM. Uptake into mouse brain of four compounds present in the psychoactive beverage kava. J Pharm Sci 1988; 77: 1003-1006

[24] Pantano F, Tittarelli R, Mannocchi G, Zaami S, Ricci S, Giorgetti R, Terranova D, Busardo FP, Marinelli E. Hepatotoxicity induced by "the 3Ks": kava, kratom and khat. Int J Mol Sci 2016; 17: 580

[25] Smith TE, Djang M, Velander AJ, Downey CW, Carroll KA, van Alphen S. Versatile asymmetric synthesis of the kavalactones: first synthesis of (+)-kavain. Org Lett 2004; 6: 2317-2320

[26] Dinh LD, Simmen U, Bueter KB, Bueter B, Lundstrom K, Schaffner W. Interaction of various Piper methysticum cultivars with CNS receptors in vitro. Planta Med 2001; 67: 306-311

[27] Jussofie A, Schmiz A, Hiemke C. Kavapyrone enriched extract from Piper methysticum as modulator of the GABA binding site in different regions of rat brain. Psychopharmacology (Berl) 1994; 116: 469-474

[28] Chua HC, Christensen ET, Hoestgaard-Jensen K, Hartiadi LY, Ramzan I, Jensen AA, Absalom NL, Chebib M. Kavain, the major constituent of the anxiolytic kava extract, potentiates GABAA receptors: functional characteristics and molecular mechanism. PLoS One 2016; 11: e0157700

[29] Friese J, Gleitz J. Kavain, dihydrokavain, and dihydromethysticin noncompetitively inhibit the specific binding of $[3 \mathrm{H}]$-batrachotoxinin-A 20alpha-benzoate to receptor site 2 of voltage-gated $\mathrm{Na}+$ channels. Planta Med 1998; 64: 458-459

[30] Schirrmacher K, Busselberg D, Langosch JM, Walden J, Winter U, Bingmann D. Effects of ( \pm )-kavain on voltage-activated inward currents of dorsal root ganglion cells from neonatal rats. Eur Neuropsychopharmacol 1999; 9: 171-176

[31] Uebelhack R, Franke L, Schewe HJ. Inhibition of platelet MAO-B by kava pyrone-enriched extract from Piper methysticum Forster (kava-kava). Pharmacopsychiatry 1998; 31: 187-192

[32] Khatri DK, Juvekar AR. Kinetics of inhibition of monoamine oxidase using curcumin and ellagic acid. Pharmacogn Mag 2016; 12: S116-S120

[33] Novaroli L, Reist M, Favre E, Carotti A, Catto M, Carrupt PA. Human recombinant monoamine oxidase $B$ as reliable and efficient enzyme source for inhibitor screening. Bioorg Med Chem 2005; 13: 6212-6217

[34] Son SY, Ma J, Kondou Y, Yoshimura M, Yamashita E, Tsukihara T. Structure of human monoamine oxidase $A$ at 2.2-A resolution: the control of opening the entry for substrates/inhibitors. Proc Natl Acad Sci U S A 2008; 105: 5739-5744

[35] Da Prada M, Zurcher G, Wuthrich I, Haefely WE. On tyramine, food, beverages and the reversible MAO inhibitor moclobemide. I Neural Transm Suppl 1988; 26: 31-56

[36] Flockhart DA. Dietary restrictions and drug interactions with monoamine oxidase inhibitors: an update. J Clin Psychiatry 2012; 73 (Suppl. 1): $17-24$

[37] Petzer A, Pienaar A, Petzer JP. The inhibition of monoamine oxidase by esomeprazole. Drug Res (Stuttg) 2013; 63: 462-467

[38] Mostert S, Petzer A, Petzer JP. Indanones as high-potency reversible inhibitors of monoamine oxidase. ChemMedChem 2015; 10: 862-873

[39] Strydom B, Bergh J], Petzer JP. The inhibition of monoamine oxidase by 8 (2-phenoxyethoxy)caffeine analogues. Arzneimittelforschung 2012; 62: 513-518

[40] Petzer A, Harvey BH, Wegener G, Petzer JP. Azure B, a metabolite of methylene blue, is a high-potency, reversible inhibitor of monoamine oxidase. Toxicol Appl Pharmacol 2012; 258: 403-409 